\title{
Condensation of the highest occupied molecular orbital within the electron localization function domains
}

\author{
E CHAMORRO,${ }^{1, *}$ M DUQUE,${ }^{1} \mathrm{C}$ CÁRDENAS,${ }^{1} \mathrm{~J}^{2}$ SANTOS,${ }^{2,3} \mathrm{~W}$ TIZNADO ${ }^{2}$ and \\ P FUENTEALBA ${ }^{2}$ \\ ${ }^{1}$ Departamento de Ciencias Químicas, Facultad de Ecología y Recursos Naturales, Universidad Andres \\ Bello (UNAB), Av. República 275, Santiago. Chile \\ ${ }^{2}$ Departamento de Física, Facultad de Ciencias, Universidad de Chile, Las Palmeras 3425, Santiago, Chile \\ ${ }^{3}$ Preselnt address: Universidad Tecnica Federico Santamaria, Departmento de Quninica, Casilla 110-V, \\ Valparaiso, Chile \\ e-mail: echamorro@unab.cl
}

\begin{abstract}
Use of regions of space defined by topological analysis of electron localization function (ELF) as reactivity descriptors is explored. By starting from the fact that the ELF presents high values in the regions where it is most probable to find an electron pair and that the square of the HOMO is a good measure of the reactivity of a molecule, it is proposed that the integration of the square of the HOMO over the volumes defined by the ELF should be a local index for predicting the most nucleophilic site of a molecule. We present here some computational results on simple systems in order to get some insights about this possibility.
\end{abstract}

Keywords. Electron localisation functions (ELF); highest occupied molecular orbital; Fukui function.

\section{Introduction}

Chemical reactivity theory is concerned with the exploration of response proclivities of a system to external perturbations. Density functional theory (DFT) ${ }^{1}$ provides a fruitful conceptual framework for the development of such a perturbative chemical reactivity theory framed on Taylor expansions of energy functionals. Hence, well known global, local and non-local hierarchies of chemical reactivity indices have been defined within such a context in terms of the coefficient expansions up to an arbitrary order. Electronic responses and nuclear indices form thus a rich and powerful framework for the exploration of chemical reactivity. ${ }^{2}$

Within the context of such a chemical reactivity theory and in direct connection with the Fukui frontier reactivity theory, conceptual DFT provides a key local descriptor of selectivity, the Fukui function, $f(\mathbf{r}),{ }^{3}$ defined in terms of the variation of chemical potential with respect to changes in the external potential $\mathbf{v}(\mathbf{r})$ or equivalently as the derivative of electron density with respect to changes in the number of electrons $N$.

$$
f(\mathbf{r}) \equiv\left[\frac{\delta \mu}{\delta v(\mathbf{r})}\right]_{N}=\left[\frac{\partial \rho(\mathbf{r})}{\partial N}\right]_{v(\mathbf{r})} .
$$

\footnotetext{
*For correspondence
}

Therefore within a frozen orbital approximation, the right hand derivative given in (1) reduces simply to the frontier $\alpha$ molecular orbital density, ${ }^{4}$

$$
f^{\alpha}(\mathbf{r}) \approx \rho^{\alpha}(\mathbf{r}) \equiv\left|\phi^{\alpha}(\mathbf{r})\right|^{2},
$$

which is the fundamental idea of the frontier molecular orbital reactivity theory developed 50 years ago by Fukui, Woodward, Hoffmann, Klopmann and Salem among many others. ${ }^{5-7}$ It is noted that in the context of the Kohn-Sham scheme, the frontier orbital density defines the Fukui function exactly, ${ }^{8}$

$$
f_{s}(\mathbf{r}) \equiv\left[\frac{\delta \mu}{\delta v_{k s}(\mathbf{r})}\right]_{N}=\left|\phi_{k s}^{\alpha}(\mathbf{r})\right|^{2},
$$

where $\mathbf{V}_{k s}(\mathbf{r})$ is the effective Kohn-Sham potential. In our group, this condensed function has been successfully applied to local organic chemical reactivity problems such as protonation of amines, ${ }^{9}$ gas phase acidity, ${ }^{10}$ empirical energy-density Hammett-like relationships, ${ }^{11}$ scales of electrophilicity, ${ }^{12}$ and regioselectivity of pericyclic reactions. ${ }^{13}$ The model condensed Fukui function $f_{k}^{\alpha}$ has been explicitly related with other condensed local indexes such as the softness, the electrophilicity, ${ }^{14}$ and more recently with some models 
of nucleophilicity. ${ }^{15,16}$ Basis-set dependence and solvent effects on these types of condensed Fukui descriptors have been also examined. ${ }^{17}$ In the same context, Chattaraj has introduced a general regional philicity index. ${ }^{18}$

On the other hand, it is also well known that the electron pair concept plays a fundamental role in the understanding of structure and reactivity in chemistry. ${ }^{19}$ In this context, it becomes of particular relevance the Electron Localization Function (ELF) proposed by Becke and Edgecombe ${ }^{20}$ within the framework of a natural Taylor expansion of the pair density probability function for electrons of identical spin (i.e. the Fermi hole). The ELF can be written as,

$$
\eta(\mathbf{r})=\left[1+\left(\frac{D_{\sigma}(\mathbf{r})}{D_{\sigma}^{0}(\mathbf{r})}\right)^{2}\right]^{-1},
$$

where $D_{\sigma}$ and $D_{\sigma}^{0}$ represent the curvature of the Fermi hole for the system under study and those for a homogeneous electron gas with the same density, respectively. Henceforth, the gradient field of ELF ${ }^{21}$ will provide us with the atomic or molecular space directly divided in regions of the space where is most probable to find an electron pair. For single determinantal wave functions the $D_{\sigma}$ term reduces to

$$
\begin{aligned}
D_{\sigma}(\mathbf{r}) & =\frac{1}{2} \sum_{1=1}^{N}\left|\nabla \phi_{i}(\mathbf{r})\right|^{2}-\frac{1}{8} \frac{|\nabla \rho(\mathbf{r})|^{2}}{\rho(\mathbf{r})} \\
& =t_{s}(\mathbf{r})-t_{w}(\mathbf{r}),
\end{aligned}
$$

which stands simply for the difference between the positive definite local kinetic energy of a system of $N$ noninteracting fermions, $t_{s}(\mathbf{r})$, with the same density $\rho(\mathbf{r})$ of the real system, and those one for the von Weizaecker kinetic energy density, $t_{w}(\mathbf{r})$. Therefore, this important term can be interpreted directly as the excess of local kinetic energy density due to the Pauli repulsion. ${ }^{22}$ Hence, topological analysis of ELF becomes relevant to the investigation of the electron localization and bonding nature within a framework of chemical reactivity theory.

In this work, it is proposed that the integration of the square of the HOMO, which can be thought as the Fukui function of a donor system, over the regions of the space defined by the ELF should give a measure of the proclivity of a determined region of the space to an electrophilic attack. Notice, that this region of the space is not confined only to the atoms but also could be a bond region or the region of an electron pair. The idea is clearly based on the way to condense the Fukui function. However, it is not so general and one cannot define in this form a condensed Fukui function because the integration over the square of the lowest unoccupied molecular orbital (LUMO) thought of as the Fukui function of an acceptor system, has no chemical meaning because the ELF does not present attractors at the regions of the space where the molecule is deficient on electrons.

In the context of recent related work, ${ }^{22,23}$ here we introduce a local descriptor through the condensation of the $\alpha=$ HOMO in the ELF regions,

$$
f_{\Omega}^{\alpha} \equiv \int_{\Omega} \rho_{\alpha}(\mathbf{r}) \mathrm{d} \mathbf{r}=\sum_{\mu}^{N \text { Basis }} c_{\mu}^{\alpha} \sum_{v}^{N \text { Nbasis }} c_{v}^{\alpha} S_{\mu v, \Omega},
$$

where the $S_{\mu v, \Omega}$ are the basis-set overlap integrals evaluated only on the domain $\Omega$,

$$
S_{\mu v, \Omega}=\int_{\Omega} \chi_{\mu}(\mathbf{r}) \chi_{v}(\mathbf{r}) \mathrm{d} \mathbf{r} .
$$

\section{Computational details}

We explore the performance of the proposed model for some simple systems such as $\mathrm{H}_{2} \mathrm{O}, \mathrm{H}_{2} \mathrm{~S}, \mathrm{C}_{2} \mathrm{H}_{4}, \mathrm{CO}$, and $\mathrm{CN}^{-}$. All optimizations have been performed using the Gaussian 98 package of programs. ${ }^{24}$ The topological analysis of the electron localization function has been performed with the TopMod suite of programs. ${ }^{25}$ Simple modifications have been introduced in the rho_int.f routine in order to calculate the topologicaldefined indexes given in (6) and (7).

We recall here that the average number of electrons localized in any basin $\Omega, \bar{N}_{\Omega}$, is defined by integrating the total electron density probability in such a region of the space:

$$
\bar{N}_{\Omega} \equiv \int_{\Omega} \rho(\mathbf{r}) \mathrm{d} \mathbf{r} .
$$

where the electron density in a Kohn-Sham context ${ }^{26}$ is calculated through,

$$
\rho(\mathbf{r})=\left[\sum_{i} n_{i} \rho_{i}(\mathbf{r})\right] .
$$

Furthermore, the population variance, $\sigma^{2}\left(\tilde{N}_{i}\right)$ (i.e., the quantum uncertainty of the basin population), can be calculated as, 
Table 1. Basis set effect on the calculation of topological Fukui functions for $\mathrm{H}_{2} \mathrm{O}$ at the B3LYP theoretical model.

\begin{tabular}{|c|c|c|c|}
\hline Basis & Basin, $\Omega$ & $N_{\Omega}\left(\sigma^{2} ; \lambda\right)$ & $f_{\Omega}^{\mathrm{HOMO}}$ \\
\hline $6-311++\mathrm{G}(3 d f, 2 p)$ & $\begin{array}{l}\mathrm{C}(\mathrm{O}) \\
\mathrm{V}(\mathrm{H} 1, \mathrm{O}) \\
\mathrm{V}(\mathrm{O})\end{array}$ & $\begin{array}{l}2.10 \text { e }(0 \cdot 36 ; 0 \cdot 17) \\
1.65 \text { e }(0.78 ; 0.47) \\
2.30 \text { e }(1 \cdot 08 ; 0.47)\end{array}$ & $\begin{array}{l}0 \cdot 04 \\
0 \cdot 08 \\
0 \cdot 40\end{array}$ \\
\hline $6-311++\mathrm{G}(d, p)$ & $\begin{array}{l}\mathrm{C}(\mathrm{O}) \\
\mathrm{V}(\mathrm{H} 1, \mathrm{O}) \\
\mathrm{V}(\mathrm{O})\end{array}$ & $\begin{array}{l}2.10 \text { e }(0 \cdot 36 ; 0 \cdot 17) \\
1.69 \text { e }(0.79 ; 0.47) \\
2.25 \text { e }(1 \cdot 06 ; 0.47)\end{array}$ & $\begin{array}{l}0 \cdot 04 \\
0 \cdot 08 \\
0 \cdot 40\end{array}$ \\
\hline $6-31+\mathrm{G}(d)$ & $\begin{array}{l}\mathrm{C}(\mathrm{O}) \\
\mathrm{V}(\mathrm{H} 1, \mathrm{O}) \\
\mathrm{V}(\mathrm{O})\end{array}$ & $\begin{array}{l}2.10 \text { e }(0 \cdot 36 ; 0 \cdot 17) \\
1.59 \text { e }(0.75 ; 0.47) \\
2.36 \text { e }(1.09 ; 0.46)\end{array}$ & $\begin{array}{l}0 \cdot 04 \\
0 \cdot 06 \\
0 \cdot 42\end{array}$ \\
\hline $6-31 \mathrm{G}(d)$ & $\begin{array}{l}\mathrm{C}(\mathrm{O}) \\
\mathrm{V}(\mathrm{H} 1, \mathrm{O}) \\
\mathrm{V}(\mathrm{O})\end{array}$ & $\begin{array}{l}2.09 \text { e }(0.36 ; 0.17) \\
1.53 \text { e }(0.73 ; 0.48) \\
2.43 \text { e }(1.09 ; 0.47)\end{array}$ & $\begin{array}{l}0 \cdot 04 \\
0 \cdot 06 \\
0 \cdot 42\end{array}$ \\
\hline STO-3G & $\begin{array}{l}\mathrm{C}(\mathrm{O}) \\
\mathrm{V}(\mathrm{H} 1, \mathrm{O}) \\
\mathrm{V}(\mathrm{O})\end{array}$ & $\begin{array}{l}2.03 \text { e }(0.30 ; 0 \cdot 15) \\
1.37 \text { e }(0.65 ; 0.47) \\
2.61 \text { e }(1.05 ; 0.47)\end{array}$ & $\begin{array}{l}0 \cdot 04 \\
0 \cdot 08 \\
0 \cdot 40\end{array}$ \\
\hline
\end{tabular}

$$
\begin{aligned}
\sigma^{2}\left(\tilde{N}_{i}\right) & =\int_{\Omega_{i}} \mathrm{~d} \mathbf{r}_{1} \int_{\Omega_{i}} \mathrm{~d} \mathbf{r}_{2} \pi\left(\mathbf{r}_{1}, \mathbf{r}_{2}\right)+\tilde{N}_{i}-\left[\tilde{N}_{i}\right]^{2} \\
& =\sum_{i \neq j} B_{i j}=\sum_{i \neq j}-\int_{\Omega_{i}} \mathrm{~d} \mathbf{r}_{1} \int_{\Omega_{j}} \mathrm{~d} \mathbf{r}_{2} \rho\left(\mathbf{r}_{1}\right) \rho\left(\mathbf{r}_{2}\right) h\left(\mathbf{r}_{1}, \mathbf{r}_{2}\right) \mathrm{d} \mathbf{r}_{2},
\end{aligned}
$$

where $h\left(\mathbf{r}_{1}, \mathbf{r}_{2}\right)$ stands for the exchange correlation hole. The variance represents the variation on the number of electrons resulting from the interaction of $\Omega_{i}$ with other basins. Furthermore, a covariance analysis (i.e., fluctuation of electron populations) based on (10) is a useful tool for the examination of the electronic delocalization pattern involving pairs of basins. ${ }^{27}$ For instance, the $B_{i j}$ term values in (10) are divided by the $\sigma^{2}(i, j)$ in order to obtain these contributions in percentages useful for the examination of the nature of bonding in several cases. ${ }^{27,28}$ Also a relative fluctuation $\lambda\left(\tilde{N}_{i}\right)$ index,

$$
\lambda\left(\tilde{N}_{i}\right)=\sigma^{2}\left(\tilde{N}_{i}\right) / \tilde{N}_{i}
$$

has proved to be a useful tool to characterize the delocalization of a given population in a particular 3D domain. Both the $\sigma^{2}(i, j)$ and $\lambda\left(\tilde{N}_{i}\right)$ might be important in the characterization of local quantities

\section{Results and discussion}

In table 1 , the results for the water molecule using various different basis sets are displayed. From the very primitive STO-3G up to one with diffuse and polarization functions. The condensed ELF presents almost no variations with the different basis sets demonstrating its numerical stability. Note that the fluctuations are also very independent of the quality of the basis set. Results using HF theory (not included here) are almost identical, although as it is already known, the measure of the electron delocalization indicated by the $\sigma^{2}$ and $\lambda$ values is lower in this case because they do not take into account the electron correlation effects. $^{21,25,27}$ The structure of ELF basins is the same in each case: a core region, $\mathrm{C}(\mathrm{O})$, associated with the inner electrons of the oxygen atom; two valence protonated basins, $\mathrm{V}(\mathrm{H} 1, \mathrm{O})$ and $\mathrm{V}(\mathrm{H} 2, \mathrm{O})$, associated with the bonding pairs between the oxygen and hydrogen atoms; and two monosynaptic basins, $\mathrm{V}(\mathrm{O})$, which are associated with the oxygen lone pairs region. The index predicts in all cases the nucleophilic regions of $\mathrm{H}_{2} \mathrm{O}$ naturally located on lone pair $\mathrm{V}(\mathrm{O})$ domain. Lone pairs at oxygen are the natural targets for an interaction with an electrophile agent.

\subsection{Describing lone pairs and bonds reactivity}

Reactivity of lone pair and bonds for some selected systems are reported in table 2 and scheme 1 . For the molecules $\mathrm{H}_{2} \mathrm{O}, \mathrm{NH}_{3}, \mathrm{CO}, \mathrm{H}_{2} \mathrm{~S}$, and $\mathrm{H}_{2} \mathrm{CO}$, the topological reactivity index correctly describes the valence monosynaptic basins associated with the lone pair region on the heteroatom as the most nucleophilic 

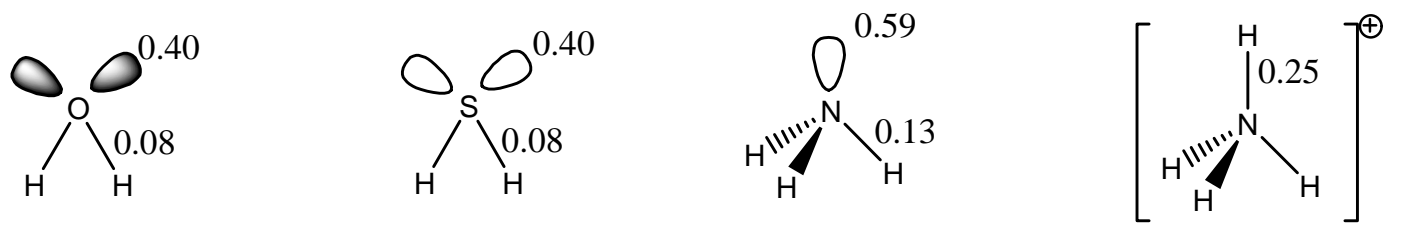<smiles>[1H][PH5]O[Na]</smiles><smiles>O=C1CCC1(O)C1(CO)CC1(O)O</smiles>

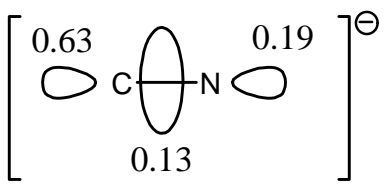

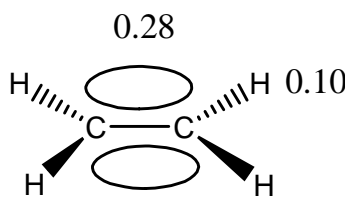<smiles></smiles>

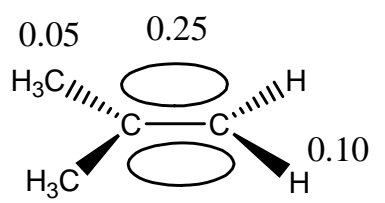

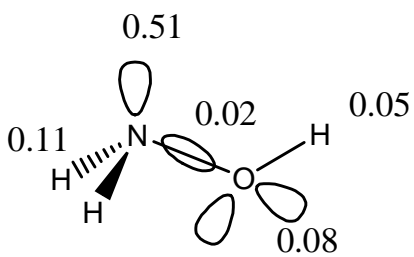<smiles>CC(C)O[Mg]</smiles>

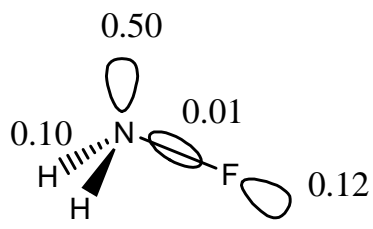

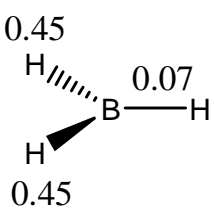<smiles>O=P(O)(O)P(O)O</smiles>

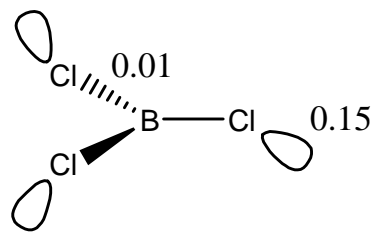

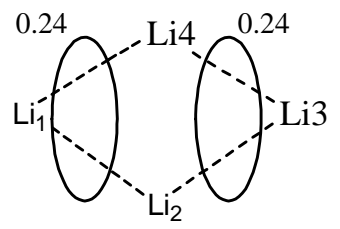

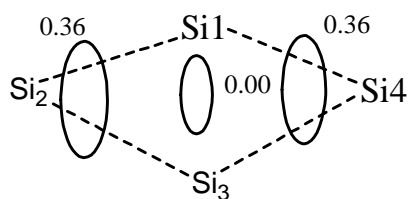

Scheme 1.

center. In the case of $\mathrm{CO}$ a greater nucleophilic character is expected from the lone pair region over the carbon atom, in agreement with experimental results.
The structure of ELF basins reproduces the Lewis model of bonding for these compounds. From the values of the topological index it is clear that nu- 
Table 2. Frozen-core topological ELF orbital function for electrophilic $\left(f_{\Omega}^{\mathrm{HOMO}}\right)$ attack on simple selected molecules at the B3LYP/6-311++G $(3 d f, 2 p)$ of theory.

\begin{tabular}{|c|c|c|c|c|c|}
\hline Molecule & Basin & $N_{\Omega}$ & $\sigma^{2}$ & $\lambda$ & $f_{\Omega}^{\mathrm{HOMO}}$ \\
\hline $\mathrm{NH}_{3}$ & $\begin{array}{l}\mathrm{C}(\mathrm{N}) \\
\mathrm{V}(\mathrm{H} 1, \mathrm{~N}) \\
\mathrm{V}(\mathrm{H} 2, \mathrm{~N}) \\
\mathrm{V}(\mathrm{H} 3, \mathrm{~N}) \\
\mathrm{V}(\mathrm{N})\end{array}$ & $\begin{array}{l}1.95 \\
1.97 \\
1.95 \\
1.95 \\
2.17\end{array}$ & $\begin{array}{l}0.34 \\
0.79 \\
0 \cdot 79 \\
0.79 \\
1.00\end{array}$ & $\begin{array}{l}0 \cdot 18 \\
0 \cdot 40 \\
0 \cdot 41 \\
0 \cdot 41 \\
0 \cdot 46\end{array}$ & $\begin{array}{l}0 \cdot 04 \\
0 \cdot 13 \\
0 \cdot 12 \\
0 \cdot 12 \\
0 \cdot 59\end{array}$ \\
\hline $\mathrm{H}_{2} \mathrm{~S}$ & $\begin{array}{l}\mathrm{C}(\mathrm{S}) \\
\mathrm{V}(\mathrm{H} 1, \mathrm{~S}) \\
\mathrm{V}(\mathrm{H} 2, \mathrm{~S}) \\
\mathrm{V}_{1}(\mathrm{~S}) \\
\mathrm{V}_{2}(\mathrm{~S})\end{array}$ & $\begin{array}{l}9.97 \\
1 \cdot 87 \\
1 \cdot 87 \\
2 \cdot 14 \\
2 \cdot 15\end{array}$ & $\begin{array}{l}0.53 \\
0 \cdot 72 \\
0 \cdot 72 \\
1.00 \\
1.00\end{array}$ & $\begin{array}{l}0 \cdot 05 \\
0 \cdot 38 \\
0 \cdot 38 \\
0 \cdot 47 \\
0 \cdot 47\end{array}$ & $\begin{array}{l}0 \cdot 04 \\
0 \cdot 08 \\
0 \cdot 08 \\
0 \cdot 40 \\
0 \cdot 40\end{array}$ \\
\hline $\mathrm{CO}$ & $\begin{array}{l}\mathrm{C}(\mathrm{C}) \\
\mathrm{C}(\mathrm{O}) \\
\mathrm{V}(\mathrm{C}, \mathrm{O}) \\
\mathrm{V}(\mathrm{C}) \\
\mathrm{V}(\mathrm{O})\end{array}$ & $\begin{array}{l}2 \cdot 06 \\
2 \cdot 15 \\
3 \cdot 08 \\
2 \cdot 55 \\
4 \cdot 15\end{array}$ & $\begin{array}{l}0 \cdot 25 \\
0 \cdot 38 \\
1.42 \\
0 \cdot 78 \\
1 \cdot 41\end{array}$ & $\begin{array}{l}0 \cdot 12 \\
0 \cdot 18 \\
0 \cdot 46 \\
0 \cdot 31 \\
0 \cdot 34\end{array}$ & $\begin{array}{l}0 \cdot 03 \\
0 \cdot 01 \\
0 \cdot 09 \\
0 \cdot 81 \\
0 \cdot 07\end{array}$ \\
\hline $\mathrm{H}_{2} \mathrm{CO}$ & $\begin{array}{l}\mathrm{C}(\mathrm{O}) \\
\mathrm{C}(\mathrm{O}) \\
\mathrm{V}(\mathrm{H} 1, \mathrm{C}) \\
\mathrm{V}(\mathrm{H} 2, \mathrm{C}) \\
\mathrm{V}(\mathrm{C}, \mathrm{O}) \\
\mathrm{V}_{1}(\mathrm{O}) \\
\mathrm{V}_{2}(\mathrm{O})\end{array}$ & $\begin{array}{l}2 \cdot 09 \\
2 \cdot 12 \\
2 \cdot 17 \\
2 \cdot 09 \\
2 \cdot 38 \\
2 \cdot 59 \\
2 \cdot 55\end{array}$ & $\begin{array}{l}0 \cdot 26 \\
0 \cdot 35 \\
0 \cdot 61 \\
0 \cdot 59 \\
1 \cdot 30 \\
1 \cdot 14 \\
1 \cdot 13\end{array}$ & $\begin{array}{l}0 \cdot 12 \\
0 \cdot 16 \\
0 \cdot 28 \\
0 \cdot 28 \\
0 \cdot 55 \\
0 \cdot 44 \\
0 \cdot 44\end{array}$ & $\begin{array}{l}0.01 \\
0.06 \\
0.31 \\
0.07 \\
0.07 \\
0.62 \\
0.62\end{array}$ \\
\hline
\end{tabular}

cleophilic domains are predicted to be located on the lone pair regions of the heteroatom for the $\mathrm{NH}_{3}$, $\mathrm{H}_{2} \mathrm{O}, \mathrm{PH}_{3}$, and $\mathrm{H}_{2} \mathrm{~S}$ systems. It can be also noted that the monosynaptic valence domain for the pair region on the carbon center, $\mathrm{V}(\mathrm{C})$, is predicted to be more nucleophilic than those corresponding to the nitrogen and oxygen centers in the $\mathrm{CN}^{-}$and $\mathrm{CO}$ species, respectively. It is clear from the values that this response quantity becomes an intramolecular reactivity descriptor and intermolecular trends cannot be discussed. This is because it simply stands for the contribution of the frontier molecular orbital to the pair regions in each particular system.

In summary, a topological-ELF index for exploring the local chemical reactivity of donor systems has been introduced. It is based on the integration of the square of the HOMO over the volumes defined by the ELF. It has been found that this index might be used to get more insights on bonding and reactivity of lone pair and bond regions. Hence, predicted $f_{\Omega}^{\mathrm{HOMO}}$ values are lower than those for properly Fukui condensed-to-site $k f_{k}^{-}$index for a given system. ${ }^{22,29,30}$ It has been already pointed out that this last model has also the disadvantage of negative and/ or out of range values when large basis set is needed.
Topological defined indexes do not suffer of this problem, becoming almost independent of the level of theory.

\section{Acknowledgements}

We acknowledge the support received from MIDEPLAN and CONICYT through the Millennium Nucleus for Applied Quantum Mechanics and Computational Chemistry, project P02-004-F. This work has been also funded by Fondecyt, grant nos. 1030173 and 1050294, and by Universidad Andrés Bello, grant no. UNABDi 16-04. MD and $C C$ are grateful to Universidad Andrés Bello (UNAB) for graduate fellowships, and WT thanks DAAD (Deutsches Akademischer Austauschdients) for a Ph.D. fellowship.

\section{References}

1. Parr R G and Yang W 1989 Density functional theory of atoms and molecules (New York: Oxford University Press)

2. Geerlings P, De Proft F and Langenaeker W 2003 Chem. Rev. 103 1793; Chermette H 1999 J. Comput. Chem. 20129 
3. Parr R G and Yang W 1984 J. Am. Chem. Soc. 105 4049; Fuentealba P and Contreras R 2002 in Reviews of modern quantum chemistry (ed.) K D Sen (Singapore: World Scientific) vol 2, p. 1013

4. Yang W and Parr R G 1985 Proc. Natl. Acad. Sci. USA 826723

5. Fukui K, Yonezawa $\mathrm{T}$ and Nagata C 1954 Bull. Chem. Soc. 27 423; Fukui K, Kato H and Yonezawa T 1961 Bull. Chem. Soc. 34 1112; Fukui K 1975 Theory of orientation and stereoselection (Berlin: Springer-Verlag)

6. Woodward R B and Hoffmann R 1969 Angew. Chem. 81 797; Woodward R B and Hoffmann R 1969 The conservation of orbital symmetry (New York: Academic Press); Woodward R B and Hoffmann R 1965 J. Am. Chem. Soc. 87395

7. Salem L 1968 J. Am. Chem. Soc. 90543 553; Salem L 1969 Chem. Brit. 5449

8. Senet P 1997 J. Chem. Phys. 1072516

9. Pérez P, Contreras R and Aizman A J. Mol. Struct. (Theochem.) 493267

10. Pérez P, Toro-Labbé A and Contreras R $2000 \mathrm{~J}$. Phys. Chem. A104 5882

11. Pérez P, Simón-Manso Y, Aizman A, Fuentealba P and Contreras R $2000 \mathrm{~J}$. Am. Chem. Soc. 1224756

12. Pérez P, Aizman A and Contreras R 2002 J. Phys. Chem. A106 3964; Pérez P, Toro-Labbé A, Aizman A and Contreras R 2002 J. Org. Chem. 674747

13. Domingo L R, Aurell M J, Pérez P and Contreras R 2002 J. Phys. Chem. A106 6871

14. Parr R G, von Szentpaly L and Liu S 1999 J. Am. Chem. Soc. 1211922

15. Contreras R, Andres J, Safont V S, Campodonico P and Santos J G 2003 J. Phys. Chem. A107 5588

16. Campodonico P, Santos J G, Andres J and Contreras R 2004 J. Phys. Org. Chem. 17273

17. Pérez P, Toro-Labbé A and Contreras R $2001 \mathrm{~J}$. Am. Chem. Soc. 1235527

18. Chattaraj P K, Maiti B and Sarkar U 2003 J. Phys. Chem. A107 4973
19. For the role of such a model into the valence shell electron repulsion theory see for instance: Gillespie R J and Hargittai I 1991 VSEPR model of molecular geometry (Boston Allyn and Bacon)

20. Becke A D and Edgecombe K E 1990 J. Chem. Phys. 925397

21. Savin A, Nesper R, Wengert S and Fässler T F 1997 Angew. Chem., Int. Ed. 36 1808; (a) Marx D and Savin A 1997 Angew. Chem., Int. Ed. 36 2077; (c) Savin A, Becke A D, Flad J, Nesper R, Preuss H and von Schnering H 1991 Angew. Chem., Int. Ed. 30 409; (d) Silvi B and Savin A 1994 Nature (London) 371 683; (e) Savin A, Silvi B and Colonna F 1996 Can. J. Chem. 74 1088; (f) Noury S, Colonna F, Savin A and Silvi B 1998 J. Mol. Struct. 54059

22. Bulat F A, Chamorro E, Fuentealba P and Toro-Labbé A 2004 J. Phys. Chem. A108 342

23. Tiznado W, Chamorro E, Contreras R and Fuentealba P 2005 J. Phys. Chem. A (in press)

24. Frisch M J et al 1998 Gaussian 98 Revision A9, Gaussian Inc Pittsburgh

25. Noury S, Krokidis X, Fuster F and Silvi B 1997 TopMoD package, Universite Pierre et Marie Curie, Noury S, Krokidis X, Fuster F and Silvi B 1999 Comput. Chem. 23597

26. Kohn W and Sham L J 1965 Phys. Rev. A140 1133

27. (a) Silvi B 2003 J. Phys. Chem. A107 3081; (b) Silvi B 2004 Phys. Chem. Chem. Phys. 6256

28. See for instance: Chamorro E, Santos J C, Gómez B, Contreras R and Fuentealba P 2001 J. Chem. Phys. 114 23; Chamorro E, Santos J C, Gómez B, Contreras $\mathrm{R}$ and Fuentealba P 2002 J. Phys. Chem. A106 11533; Chamorro E and Notario R 2004 J. Phys. Chem. A108 4099

29. Contreras R, Fuentealba P, Galván M and Pérez $\mathrm{P}$ 1999 Chem. Phys. Lett. 304405

30. Fuentealba R, Contreras P and Perez J 2000 Chem. Phys. 1132544 